\title{
36 A BROADER APPROACH TO LIMITATION OF MEDICAL TREATMENT: AUDIT OF COMPLIANCE AFTER CHANGING FROM 'NFR' TO 'GOALS OF CARE' IN AN ACUTE HOSPITAL
}

R Thomas, ${ }^{1}$ M Ashby ${ }^{1}{ }^{1}$ Palliative Care Service, Royal Hobart Hospital, Southern Tasmania Health Organisation, Australia

10.1136/bmjspcare-2013-000491.36

Background In March 2010 'Not For Resuscitation' (NFR) forms in the Royal Hobart Hospital (RHH) were replaced with a 'Goals of Care' (GOC) form that documents limitation of medical treatment in three categories: curative, palliative and terminal.

Aim To assess the uptake and completion of the GOC form within the hospital, in particular, the sections of the form that were most likely to be filled out and by whom.

Method A 'snapshot' of all patients in the RHH on 6 September 2012 was obtained. 283 patient files were reviewed for a GOC form and the completed forms were evaluated. Any Advanced Care Planning (or similar) was noted and compared with the GOC form completed. The results were compared with a previous audit of the NFR form.

Results Overall $52 \%$ of patients had a GOC form completed. Medical teams showed the greatest use of the GOC form with an uptake of $84 \%$, compared with the NFR form at 34\%. The documentation of the reason for limitation was completed in $27 \%$ of the cases. 
Discussion The GOC form has been well received within the hospital and is used more extensively than the previous 'NFR' form.

Conclusion The GOC form provides a documentation point for the overall treatment goals for the patient and is widely used by medical teams. Further improvements can be made with simplification of the form and education of non-medical specialties. It provides a clear medical decision-making framework for the deteriorating patient who is approaching the end of life. 